\title{
Economic and productivity evaluation of different horizontal drilling scenarios: Middle East oil fields as case study
}

\author{
Abbas Khaksar Manshad ${ }^{1,3} \cdot$ Milad Ebrahimi Dastgerdi $^{2} \cdot$ Jagar A. Ali ${ }^{3,4} \cdot$ Nazir Mafakheri $^{3} \cdot$ Alireza Keshavarz $^{5}$. \\ Stefan Iglauer $^{5}$. Amir H. Mohammadi ${ }^{6}$
}

Received: 12 February 2019 / Accepted: 11 May 2019 / Published online: 17 May 2019

(c) The Author(s) 2019

\begin{abstract}
Development of high-density oil and gas fields presents a great challenge to the energy industry due to the low productivity of individual wells and their high drilling cost. We thus compared the productivity, associated costs and economical revenues gained from two field development scenarios, with multilateral and horizontal drilling, to evaluate the optimal drilling and completion conditions in a giant heavy oil reservoir in the Middle East. Well path design was identified as one of the most complex parameters depending on the well-testing results, field production and reservoir simulation data. The fishbone well of four branches with a length of $300 \mathrm{~m}$ each and $30^{\circ}$ deviation from the main hole was identified to be drilled and completed using open-hole sidetrack as the best approach. The fishbone structure raised production by $393 \%$, while drilling cost only increased by $130 \%$ compared with a conventional horizontal well.
\end{abstract}

Keywords Horizontal well $\cdot$ Multilateral well $\cdot$ Fishbone well $\cdot$ Productivity $\cdot$ Economical assessment

\section{Introduction}

High costs associated with oil and natural gas production from tight and unconventional reservoirs (e.g., tight carbonate, extra heavy oil and shale oil reservoirs) pose a real challenge for petroleum companies. However, unconventional

Abbas Khaksar Manshad

akmanshad113@gmail.com

1 Department of Petroleum Engineering, Abadan Faculty of Petroleum Engineering, Petroleum University of Technology, Abadan, Iran

2 Department of Petroleum Engineering, Faculty of Engineering, Omidieyh Branch, Islamic Azad University, Khozestan, Iran

3 Department of Petroleum Engineering, Faculty of Engineering, Soran University, Soran, Kurdistan Region, Iraq

4 Department of Petroleum Engineering, College of Engineering, Knowledge University, Erbil, Kurdistan Region, Iraq

5 School of Engineering, Edith Cowan University, Joondalup, WA 6027, Australia

6 Institut de Recherche en Génie Chimique et Pétrolier (IRGCP), Paris Cedex, France reservoirs are predicted to supply a significant share of the global energy in future decades, despite difficulties producing them (Xing et al. 2012; Elyasi 2016). Horizontal drilling can be applied as a significant solution, despite its high cost (Ali et al. 2004; Jinghong et al. 2017) Technically, horizontal wells can increase productivity, improve areal sweep efficiency, minimize water and gas coning, bridge vertical fractures and prevent asphaltenes precipitation (Wang et al. 2017). However, although horizontal wells showed fair production enhancement in many fractured reservoirs, in some cases the productivity improvement was not significant compared to other well plan scenarios (Wang et al. 2017). In addition, the major obstacle related to horizontal wells is rapid well productivity decline due to fracture closure, orientation and absence of knowledge of the reservoir's fracture geometry (Rice et al. 2014). Meanwhile, drilling technology development introduced the option of multilateral wells (Zhou et al. 2008). Such multilateral wells have shown great potential for cost-effective field development in tight oil and gas fields (Dongbo et al. 2013; Zehao et al. 2019; Ayokunle and Hashem 2016).

The ultimate goal of this study was to perform a simulation and optimization to identify the best drilling scenario in a problematic reservoir. Thus, we compared different drilling scenarios to optimize the well setting for a giant oil 
Table 1 Characteristics of target reservoir used in this study

\begin{tabular}{ll}
\hline Reservoir Items & Target reservoir \\
\hline Reservoir depth & $2709-2850 \mathrm{~m}$ \\
Net pay & $118 \mathrm{~m}$ \\
Lithology & Bioclastic limestone \\
Core permeability & $3-8 \mathrm{md}$ \\
Crude oil gravity & $19.95 \mathrm{API}=934 \mathrm{~kg} / \mathrm{m}^{3}$ \\
Solution GOR & $276-441 \mathrm{SCF} / \mathrm{STB}$ \\
Formation oil viscosity & $4.44-5.44 \mathrm{cp}$ \\
Recovery factor & $19 \%$ \\
Reservoir pressure & $317.2-346.7 \mathrm{bar}$ \\
Horizontal (KOP) & $2974 \mathrm{~m}$ \\
Rig days for a sample well & $99 \mathrm{days}$ \\
Mud weight & $1.22-1.25 \mathrm{gm} / \mathrm{cm}^{3}$ \\
\hline
\end{tabular}

Table 2 Formation inclination of drilled well to the target reservoir

\begin{tabular}{|c|c|c|c|c|}
\hline \multirow[b]{2}{*}{ Formation } & \multicolumn{2}{|c|}{ Inclination around well $\left({ }^{\circ}\right)$} & \multicolumn{2}{|c|}{$\begin{array}{l}\text { Inclination in Border } \\
\left(^{\circ}\right)\end{array}$} \\
\hline & Eastern flank & Western flank & Eastern flank & $\begin{array}{l}\text { West- } \\
\text { ern } \\
\text { flank }\end{array}$ \\
\hline A & 1 & 3 & 2.5 & 4 \\
\hline $\mathrm{B}$ & 0 & 2 & 2.5 & 3 \\
\hline $\mathrm{C}$ & 1.5 & 1.5 & 2 & 2 \\
\hline
\end{tabular}

field in the Middle Eastern. The optimal scenario identified showed promising productivity results with a critical discussion about financial implications.

\section{Reservoir characteristics}

Here, we present a case study for a giant Middle Eastern oil field, and its characteristics are summarized in Table 1. As shown in the table, the target reservoir consists of a crude oil of $19.95^{\circ} \mathrm{API}, 4.44-5.44 \mathrm{cP}$ viscosity and 276-441 SCF/ STB gas-to-oil ratio (GOR). Hydrocarbons are produced from three different reservoirs (A, B and C), which pose some production challenges (Table 2). In this work, reservoir "A" with the net pay $118 \mathrm{~m}$ located at different depths about 2709 to $2850 \mathrm{~m}$ was considered as a target reservoir. Based on company's initial oil field development plan, production profile was supposed to reach $250 \mathrm{MBOPD}$ at the plateau which never reached the goal (Fig. 1). This reservoir is near to a residential area; therefore, the protection of the environmental and operational hazards is critical. Hence, it makes multilateral well a suitable candidate in the region as the required surface facilities and the network pipelines would be minimized in this configuration, and consequently, it may end up with decrease in surface pollution and underground water pollution. Although clearly multilateral wells are favorable configurations for critical environmental condition (Mendes et al. 2014), multilateral wells also are expected to increase the current recovery factor (19\% based on an old development plan from company's report). A horizontal well with the KOP $2974 \mathrm{~m}$ has been drilled in 99 days using a mud weight between 1.22 to $1.25 \mathrm{gm} / \mathrm{cm}^{3}$.

\section{Field development plan}

Production profile prediction based upon old version of field development plan is demonstrated in Fig. 1. As shown in the figure, the average production rate for each individual horizontal well was 1570 BOPD which does not see the production needs and FDP desires.

The well-testing results including drill stem test (DST) and repeated formation test (RFT) of the well are shown in Fig. 2. Figure 2a presents the DST results which confirm that there are abnormal pressure zones in the drilled well. Additionally, RFT of the offset wells shown in Fig. 2b presents high heterogeneity in the reservoir; thus, different wells have a different performance. Formation pore pressure coefficient (FPPC) for the objective well is between
Fig. 1 Production profile prediction of the field for 30 years dependent of the old version of FDP

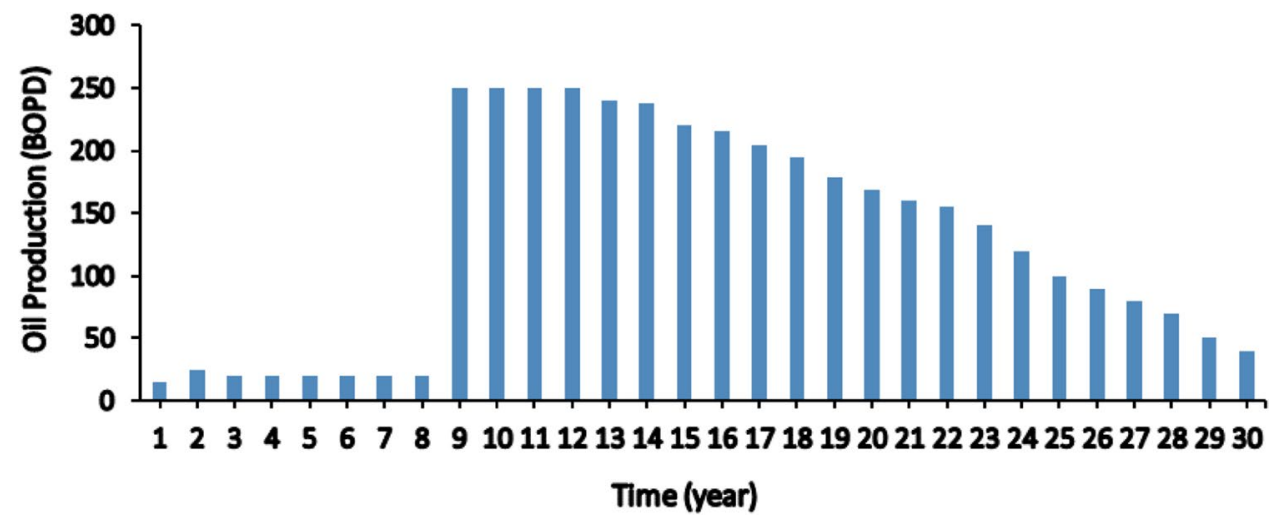




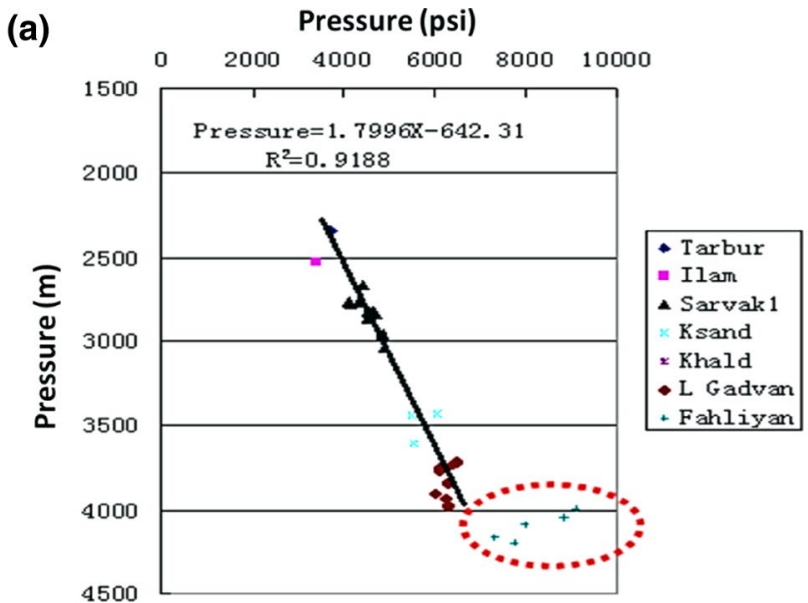

(b)

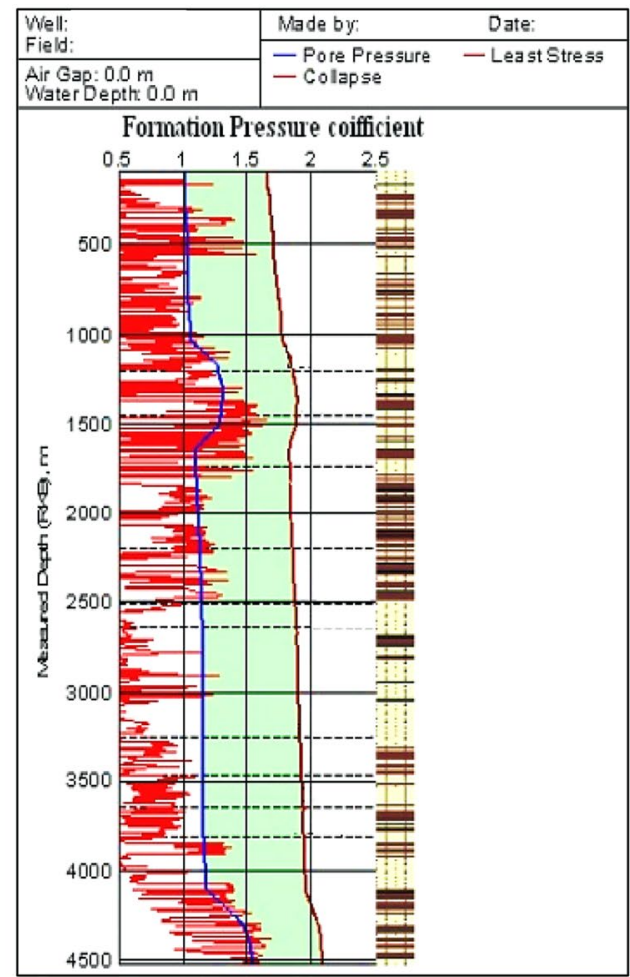

Fig. 2 Well-testing results of the studied field: a quantitative pore pressure test and $\mathbf{b}$ RFT results for the offset well

1.16 and 1.29 which is significant compared to the offset wells. Another important factor which needs to be considered is the need for gas lifting after 5 years of production. Having said that, average oil well production has been chosen as a comparison parameter in different scenarios (Hasan et al. 2017). Based on the present reservoir simulation model, the oil well with 2000 m horizontally extended into the reservoir showed maximum production rate and extending the well length above $2000 \mathrm{~m}$ does not enhance the production rate. However, available technologies could make 600 to $800 \mathrm{~m}$ contact with the reservoir formation.

\section{Horizontal well scenarios}

In this work, fishbone configuration as one of the most common multilateral well designs has been studied in detail. This configuration was enabled to maximize the reservoir contact and hence the productivity of the well. Then, the optimization of multilateral wells under reservoir conditions has been compared with the equivalent horizontal well by conducting reservoir simulation models for the target Reservoir (Bera and Belhaj 2016). Experimental design technique was used to study the relative impact of five key parameters in designing the optimum configuration of the multilateral well. Selected parameters for the present study were length of main hole, length of side track, space between side tracks, number of side tracks, and angle between side track and main hole. The objective function was the productivity and drilling capital and operation costs. Eventually best choice between several scenarios was chosen by using three-dimensional fine-scale numerical simulations. Individual effect of parameters and interaction plots was provided to show the relation between selected parameters and their effects on the objective function initially. According to the old field development plan and due to formation geometry and reservoir heterogeneity, more than $80 \%$ of current wells were drilled horizontally with 600 to $800 \mathrm{~m}$ extended section. The average production rate for each horizontal well was predicted as 1571 BOPD. Thus, we considered drilling a multilateral well; the design and configuration of the multilateral well can be classified as follows (Ali et al. 2005):

\begin{tabular}{ll}
\hline Multi-branched well & Lateral from vertical hole \\
Forked multilateral & Stacked laterals \\
Dual opposing laterals & Fishbone well \\
\hline
\end{tabular}

Due to low permeability and lack of developed drilling technology for drilling long sidetracks, dual-opposing laterals and stacked lateral configurations could not provide enough contact area with reservoir. Hence, these configurations were eliminated to be selected. Lateral from vertical is not suitable for a 118-m carbonate reservoir, and it needs more thickness to be favorable. Forked multilateral and multi-branched wells need longer main hole compared to fishbone wells, and this technology is not available in this oil field. Eventually, based on the old field development plan which has already been performed in combination with the reservoir geometry, available drilling technology in the region and presence of many horizontal wells in this oil field, it is concluded that fishbone well is the best scenario for this oil field. Figure 3 shows a schematic view of a typical

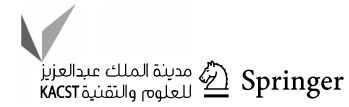






Fig. 3 General form of the schematic illustration of fishbone well with six branches to show its dimensions

fishbone well with six branches, which has the highest performance and compatibility with the available technology with minimal additional cost. To provide a proper model for fishbone wells, several parameters have been selected as the variables for reservoir simulation, as shown in Fig. 3 . The considered parameters are the main hole length of fishbone wells (L), length of sidetrack (LSDTR), space between sidetracks $(\mathrm{M})$, number of fishbone sidetracks $(\mathrm{N})$ and angle between SD and main hole (A).

The design of the experiment (DOE) was performed in order to identity and achieve the optimum well performance, as shown schematically in Fig. 4. The DOE of this study included four different sections to modify the field development plan, such as reservoir simulation model, multilateral well configuration, wellbore, stability and completion design, and productivity and economic feasibility.

Based on available information including the reservoir characteristics, well-test analysis, geology evaluation, seismic, PVT analysis and well-logging data, a reservoir model has been created in order to evaluate the performance of different multilateral well configurations. Wellbore stability of the horizontal well was also considered to select the optimal well completion using geo-mechanical model (Garrouch and Ebrahim 2001). Afterward, according to Guo et al. (2008) and Xiance et al. (2009), the reservoir model in the last section was created which shows more compatibility for carbonate fractured reservoirs. In fact, it is mathematical model that connects the reservoir radial flow concept with the fracture linear reservoir, linear flow and fracture radial flow. This model has been selected due to compatibility with current work for predicting productivity of fractured carbonate wells.

After following the mentioned procedure, effect of number of fishbone sidetracks $(\mathrm{N})$ versus oil production rate has been studied by simulation as shown in Fig. 5a. It is clear that the oil production increased by increasing number of sidetracks, but more than four sidetracks do not show a significant growth in the production rate. Another important parameter in improving oil production is the optimum length of sidetrack (LSDTR). In Fig. 5b, the length of single sidetrack longer than $300 \mathrm{~m}$ which does not show impressive increase on oil production rate, while the optimum LSDTR was identified to be $300 \mathrm{~m}$. Figure $5 \mathrm{c}$ shows the effect of angle between sidetrack and main hole (A) on production rate for all sidetracks. Between $20^{\circ}$ to $30^{\circ}$ shows optimum oil production rate.

Furthermore, Table 3 presents the details of the optimum scenario (fishbone well) identified in this study. As can be seen, the production rate in the fishbone well with four sidetracks compared to the conventional single horizontal well increased from 1570 to 6180 BOPD. Improving the daily production rate by $393 \%$ for the same reservoir is a promising outcome.

\section{Drilling and well completion}

Drilling and completion of the well are the main operation phases of the field development plan. According to the DOE used in this study, after the selection of the best scenario for field development plan from reservoir engineering point of view, the drilling and well completion design was considered. Important parameters which need to be examined include the landing point and sidetrack starting point from the main hole which is dependent on oil water contact (OWC), the geometry of well and offset drainage areas between reservoir and well. In this study, two methods for drilling and completion were considered, such as open-hole sidetrack (OHSDTR) and conventional drilling methods by whipstock. Nawaz et al. (2009) reported the following limitations of using the conventional drilling methods by whipstock:

- Whipstock setting problem.

- Possible whipstock preset setting while running in hole.

- Cutting the window's problem.

- Long fishing operation due to mill twist offs; in worst cases setting another whipstock and cutting another window.

- Milling the top of the whipstock while cutting the window leading to a severe problem in retrieving the whipstock.

Based on the company report, whipstock technology was used for the lateral sidetracks and showed only 38\% success in this oil field. Based on aforementioned problems in this section, an appropriate alternative for this method is the open-hole sidetrack (OHSDTR) which does not have the same problems related to the whipstock conventional 


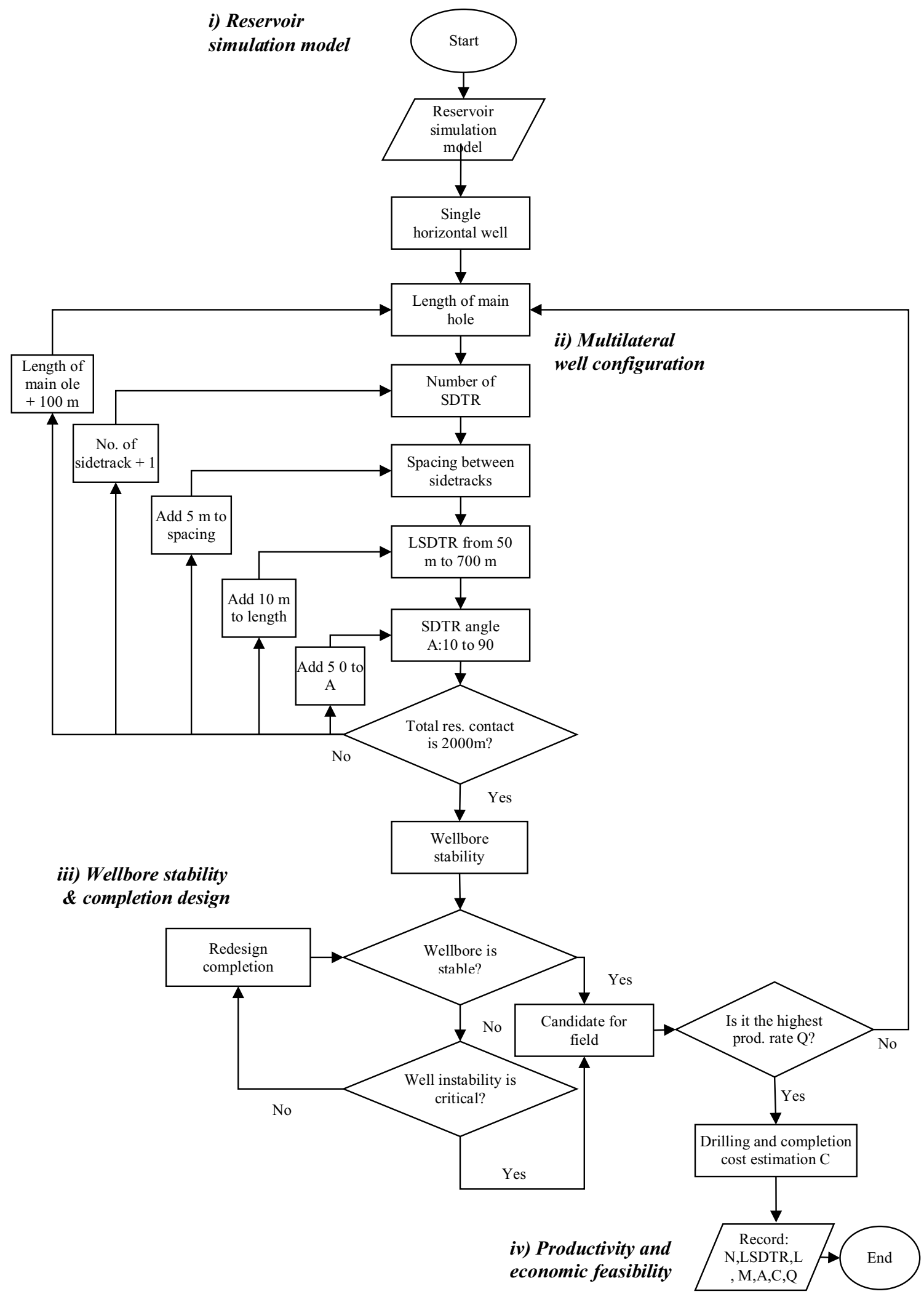

Fig. 4 Schematic diagram shows the procedural steps of a flowchart used in this study to select an optimal productivity conditions 



Fig. 5 Different rates of daily well production depend on different: a number of sidetracks, b length of sidetrack (LSDTR) and $\mathbf{c}$ angle between sidetrack and main hole (A)

Table 3 Optimum scenario details

\begin{tabular}{lllllll}
\hline Scenario & $L(\mathrm{~m})$ & $N$ & $M(\mathrm{~m})$ & LSDTR $(\mathrm{m})$ & $A\left({ }^{\circ}\right)$ & $Q(\mathrm{BOPD})$ \\
\hline Horizontal well & 800 & - & - & - & - & 1570 \\
Fishbones & 800 & 4 & $70-150$ & 300 & $20-30$ & 6180 \\
\hline
\end{tabular}

method. Therefore, well lengths after landing point of the whipstock were only between 700 to $900 \mathrm{~m}$ which led to the low production of 1571 BOPD, as mentioned earlier in Table 3. In order to increase the reservoir contact to its optimum contact length $(2000 \mathrm{~m})$, a fishbone well with four open-hole sidetracks (OHSDTR) was selected as optimum SDTR numbers. According to the results of optimization mentioned earlier by applying different scenarios of DOE, the selected fishbone design can reach 2000 m contact with the reservoir without requiring any new drilling technology. On the other hand, selection of the sidetrack starting point plays a vital role in developing a successful OHSDTR. Thus, after studying the log while drilling
(LWD) data which include image log, neutron porosity and density data, sidetrack starting point has been determined. The main hole section view and plan view of the selected well are shown in Fig. 6.

\section{Well trajectory optimization}

\section{Main hole trajectory}

Table 4 shows the well trajectories of the wells. In order to access the different reservoirs, kick of point was designed at 2130 and dogleg severity was $4.370 \mathrm{deg} / 30 \mathrm{~m}$. Thus, the well inclination of the first section reached $75^{\circ}$ to penetrate the target reservoirs "B" and " $C$ ", and the inclination 


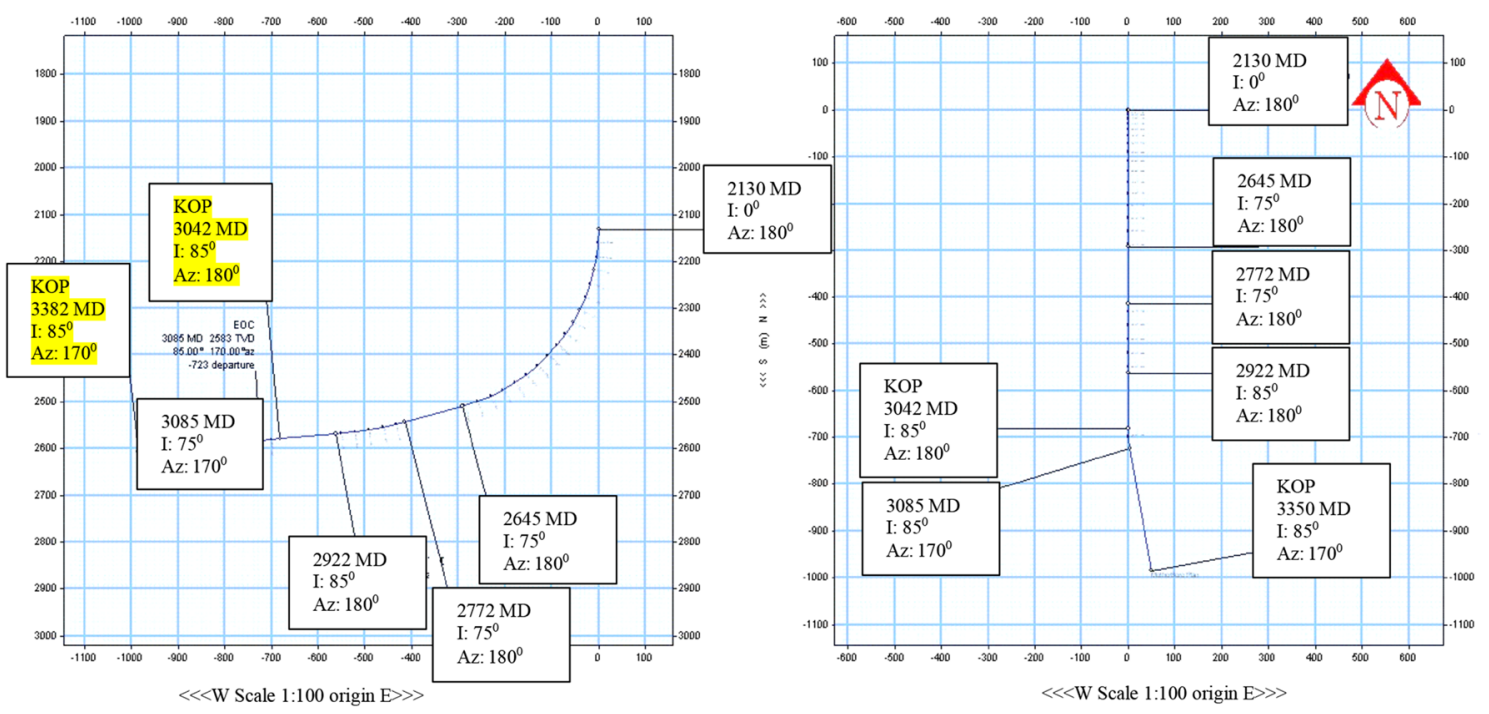

Fig. 6 Main hole section view and plan view of the selected well used in this study

Table 4 Well path trajectory of the selected well used in this study

\begin{tabular}{llllccccc}
\hline Measured depth $(\mathrm{m})$ & Inclination $\left(^{\circ}\right)$ & Azimuth $\left({ }^{\circ}\right)$ & TVD $(\mathrm{m})$ & Vertical section $(\mathrm{m})$ & NS $(\mathrm{m})$ & EW $(\mathrm{m})$ & Closure $(\mathrm{m})$ & DLS $\left({ }^{\circ} / 30 \mathrm{~m}\right)$ \\
\hline 2130.00 & 0.00 & 180 & 2130.00 & 0.00 & 0.00 & 0.00 & 0.00 & 0.00 \\
2644.99 & 75.00 & 180 & 2510.02 & -269.6 & -269.6 & 0.00 & 269.6 & 4.37 \\
2772.47 & 75.00 & 180 & 2543.01 & -414.73 & -414.73 & 0.00 & 414.73 & 0.00 \\
2922.47 & 85.00 & 180 & 2569.3 & -562.27 & -562.27 & 0.00 & 562.27 & 2.00 \\
3042.39 & 85.00 & 180 & 2579.48 & -681.73 & -681.73 & 0.00 & 681.73 & 0.00 \\
3085.08 & 85.00 & 170 & 2583.21 & -724.05 & -724.05 & 3.70 & 724.05 & 7.00 \\
3382.00 & 85.00 & 170 & 2609.09 & -1015.34 & -1015.34 & 55.06 & 1016.83 & 0.00 \\
\hline
\end{tabular}

reached $85^{\circ}$ at $2645 \mathrm{~m}$ TVD to penetrate the target reservoir "A" (Fig. 6). For designing trajectory, the drilling survey calculations are the key parameters of successful operation to control the effect of dogleg severity and minimize the effect of torque and drag. These sorts of calculations help to determine the appropriate wellbore position during drilling operation ( $\mathrm{Li}$ et al. 2007). Since minimal torque and drag are desirable for multilateral wells, dogleg severity (DLS) was determined to be between 4 and $7 \mathrm{deg} / 30 \mathrm{~m}$. Also average rate of penetration (ROP) was chosen to be $5.1 \mathrm{~m} / \mathrm{h}$. However, with increasing rotation to 35 round per minute (RPM), ROP was raised to $12 \mathrm{~m} / \mathrm{h}$. DLS was designed to be $0 \mathrm{deg} / 30 \mathrm{~m}$ between 2645 and $2772.47 \mathrm{~m}$ which is beside the main target reservoir " $A$ ", to reach the reservoir from different opening points in case that under any circumstances, well path misses the target (Fig. 6).

\section{Sidetracks 1, 2, 3 and 4}

The well trajectory azimuth changed from $180^{\circ}$ to $170^{\circ}$ while approaching the opening of the first sidetrack, as shown in Table 4. Afterward, the DLS is set on $7 \mathrm{deg} / 30 \mathrm{~m}$ to control lateral stress and maintain the successful OHSDTR operation. According to Dang et al. (2013), Economides et al. (1996) and Nawaz et al. (2009), offset wells OHSDTR experiences and to minimize friction between drill string and wellbore, 30-70 m after casing shoe was selected as the optimum point for starting SDRT 2. Designs of all selected four sidetracks are shown in Fig. 7, well path trajectory was designed from $3057 \mathrm{MD}$, sidetrack 1 deviated from main hole while inclination and azimuth are $84.98^{\circ}$ and $176.33^{\circ}$, respectively.

\section{Mechanical analysis and drilling operation functionality}

Torque and drag ( T \& D) analysis of the drill string was a necessary analysis to evaluate the mechanical failure of the drilling string. As shown in Fig. 8a, b at the depth of the target reservoir, the torque reduction of the drill string was negligible and drillstring slide force had a low value before depth of $3500 \mathrm{~m}$. As it is presented in Fig. 8c, the effective axial load does not exceed the sinusoidal buckling limit and

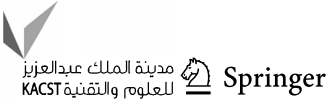




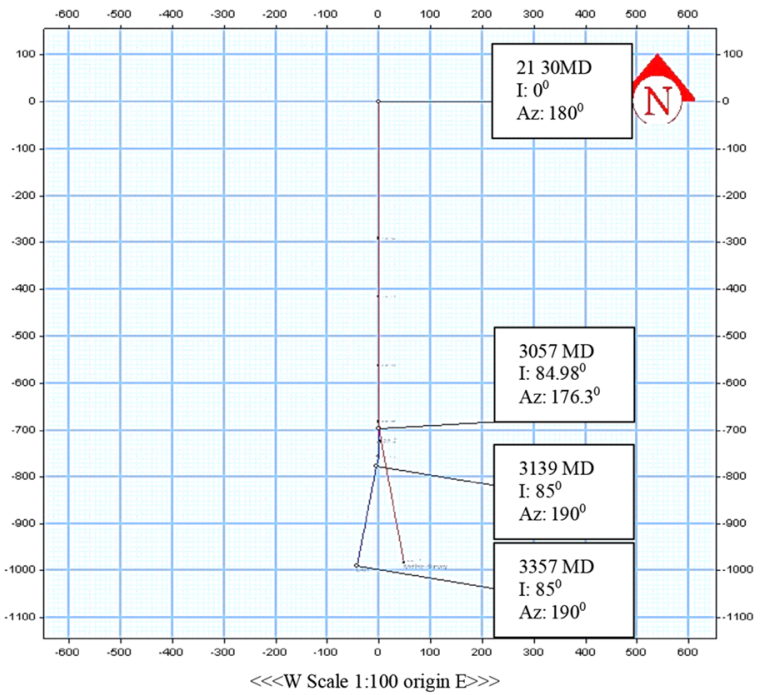

a



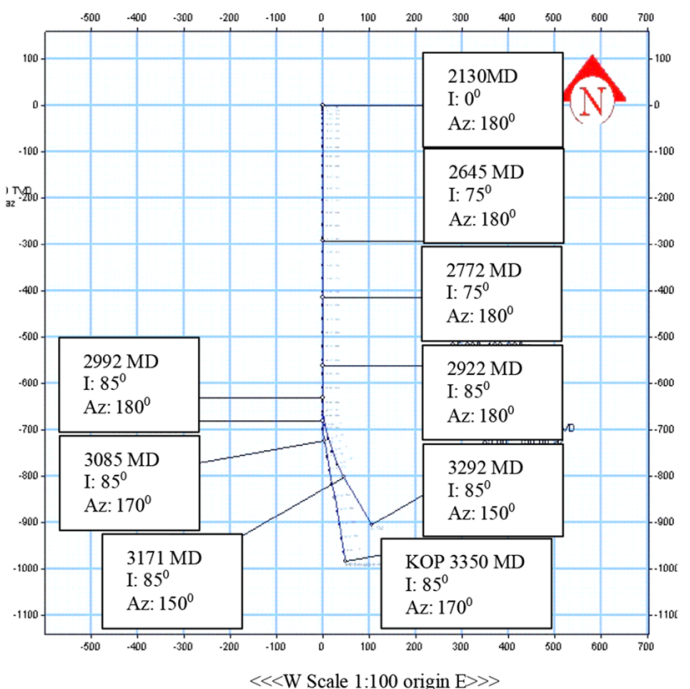

b

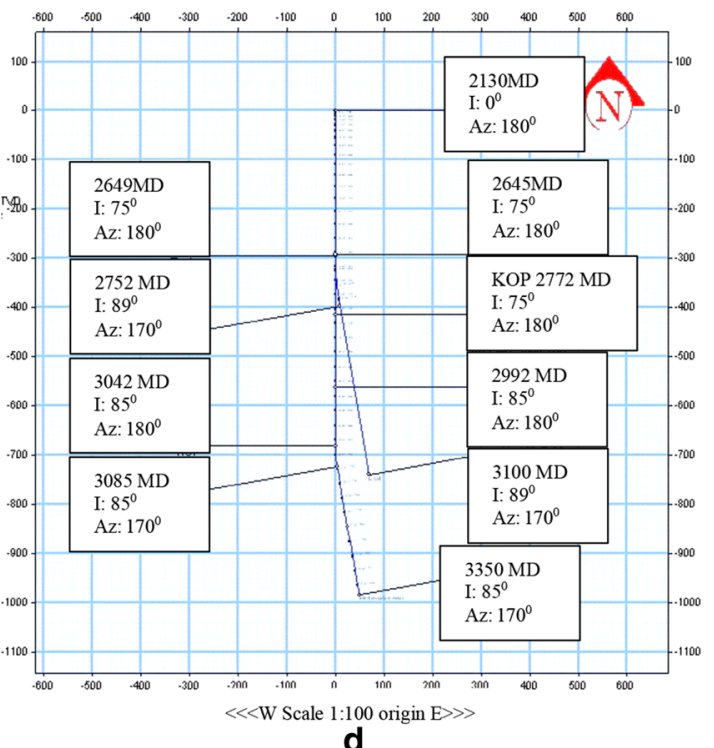

d

Fig. 7 Main hole section view and plan view of the selected well used in this study: a SDRT 1, b SDRT 2, c SDRT 3 and d SDRT 4

helical buckling limit which means there is no drillstring failure.

Figure $8 \mathrm{~d}$ shows that drillstring stress clearly is lower than $60 \%$ of the yield stress which means no drillstring failure due to high stress concentration during the drilling process. Also calculated surface torque and hookload are reported in Table 5 to check the functionality of drilling operation. Based on aforementioned mechanical analysis, fishbone scenario shows successful mechanical operation with currently available drilling technology.

Mechanical drilling consideration has a key role to ensure selected drilling operation scenarios feasibility for multilateral wells due to the complex nature of horizontal wells compared to vertical wells. As shown in Fig. 8, all mechanical criteria show successful operation. Previous studies reported (Bilgesu et al. 2007) critical situation in wellbore cleaning and mud circulation for directional wells, and it needs to be considered.

In Fig. 8e, flow rate versus rate of penetration (ROP) is plotted and results for open-hole section showed that required pump power is 306 GPM for $100 \%$ cleaning the wellbore. However, in fact, present pumps in the oil field offer only 260 GPM which leads to have $7 \%$ cutting remained in the wellbore. Fortunately, $7 \%$ remaining cutting is tolerable for horizontal wells. 

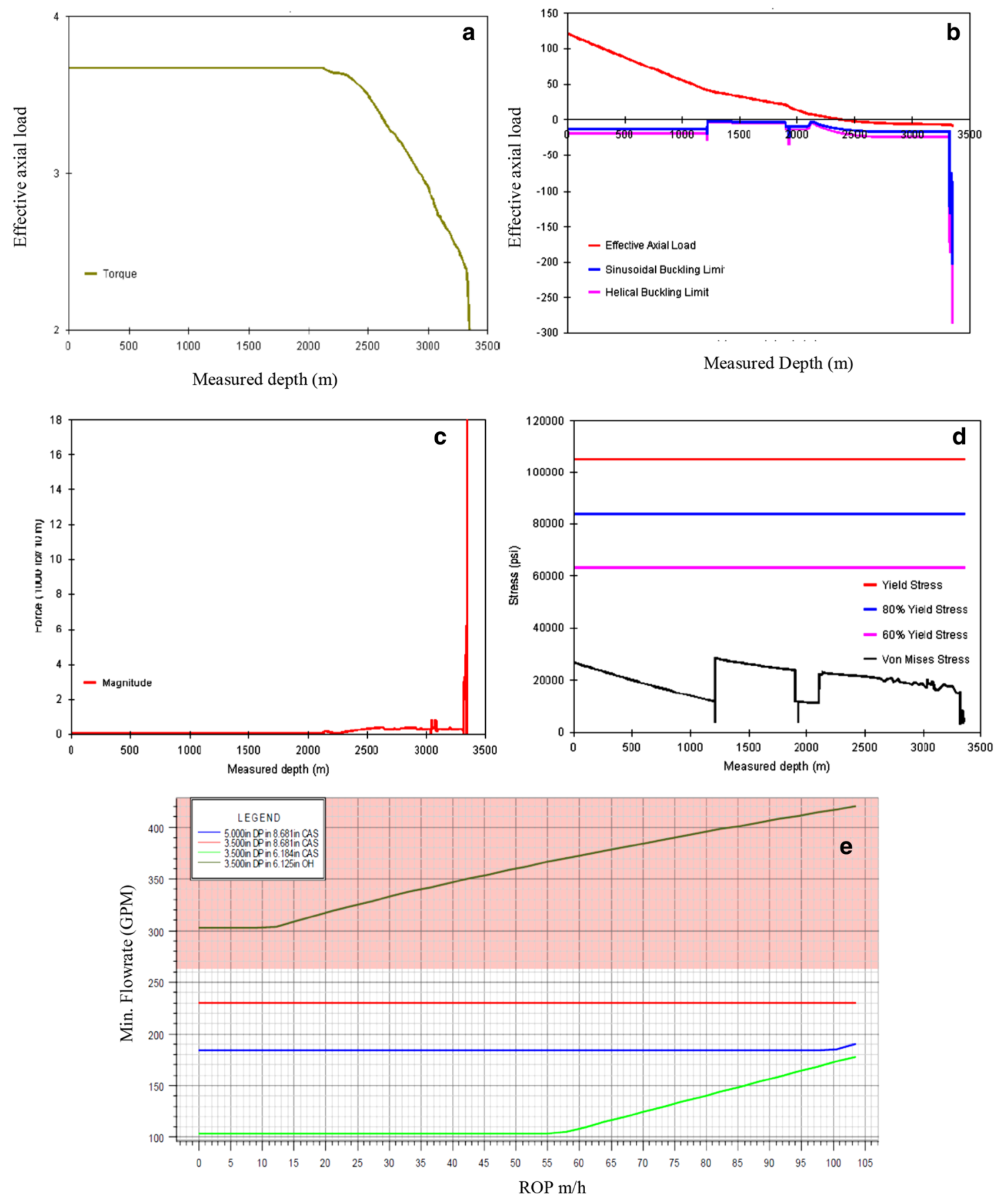

Fig. 8 a Drillstring torque reduction, $\mathbf{b}$ effective axial load, $\mathbf{c}$ drillstring slide force, $\mathbf{d}$ drillstring stress plot and $\mathbf{e}$ wellbore cleaning analysis for different sections for a borehole condition of $75 \mathrm{pcf}$ mud weight and $8 \mathrm{t}$ WOB

Table 5 Surface torque and hookload

\begin{tabular}{llllll}
\hline $\begin{array}{l}\text { Mud } \\
\text { base }\end{array}$ & $\begin{array}{l}\text { Hookload } \\
(1000 \mathrm{ft} \mathrm{lbf})\end{array}$ & $\begin{array}{l}\text { Surface } \\
\text { torque } \\
(1000 \mathrm{lbf})\end{array}$ & WOB (t) & $\begin{array}{l}\text { Mud } \\
\text { weight } \\
(\mathrm{pcf})\end{array}$ & $\begin{array}{l}\text { Circu- } \\
\text { lation } \\
(\mathrm{GPM})\end{array}$ \\
\hline WBM & 3.5 & 188.4 & $0-8$ & 75 & 260 \\
\hline
\end{tabular}

\section{Economic feasibility evaluation}

After optimization of production rate and functionality analysis of drilling and completion, economic evaluation is necessary for justification of new development plan. The main responsibility of a drilling engineer is to recommend applicable drilling procedures which can end up in successful 
completion of oil and gas wells, in the safest and most cost-effective manners. So, a new plan has been suggested considering drilling cost estimation analysis. Actually, it is impossible to identify all the characteristics of drilling operation which could affect drilling cost; however, many characteristics of the operation can be monitored. Thus, for a realistic estimation, it is essential to contemplate a set of factors that determine the total drilling costs. These total drilling costs can be broken down into variable drilling costs (which are time dependent) and fixed operating expenses (which are independent of time). Therefore, drilling costs have been categorized in eight different categories. Since an open-hole completion method has been chosen, cementing and well completion costs are considered as fixed expenditure and the rest were considered as variable costs.

- Cementing

- Well completion

- Casing and linear

- Drilling fluid

- Drill stem

- Deviated well service

- Tubing and stimulation

- Rig rent

\section{Results and discussion}

Several simulation models were investigated to obtain the optimum production scenario for aforementioned reservoir. Based on reservoir performance, the most suitable scenario was a fishbone well with four branches to cover the maximum contact between well and reservoir. To identify the best scenario, five parameters (e.g., length of main hole, length of sidetrack, space between sidetracks, number of sidetracks and angle between sidetracks and main hole) have been selected as variables which showed great impact on the productivity of multilateral wells. Applying the mentioned statistical analysis (DOE) and using the original data to evaluate the fishbone performance showed significant difference between the predicted horizontal well and fishbone well. By increasing contact area between wellbore and reservoir formation, the total production rate of fishbone well is increased significantly compared to the conventional horizontal well (Fig. 9).

Production rate forecast for single horizontal versus fishbone multilateral well based on reservoir simulation results for single horizontal well is shown in Fig. 10. As it is clear in the figure, primary recovery due to nature of the reservoir which is heavy oil and relatively tight reservoir is expected to continue production of oil till 2032. On the other hand, fishbone multilateral well is expected to continue production till 2056.

By running different simulations for the single horizontal well and the fishbone well, the total production rate of fishbone well is 3.9 times greater than the single horizontal well. On the other hand, the main challenge for real application of the alternative scenario is to justify the new plan from

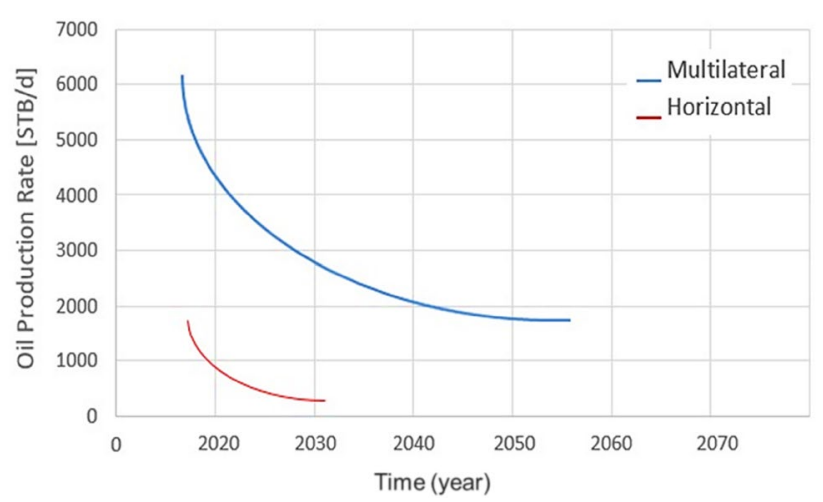

Fig. 10 Oil production rate of horizontal and multilateral wells based on the simulation outcomes
Fig. 9 Comparison of single horizontal and fishbone well production rate

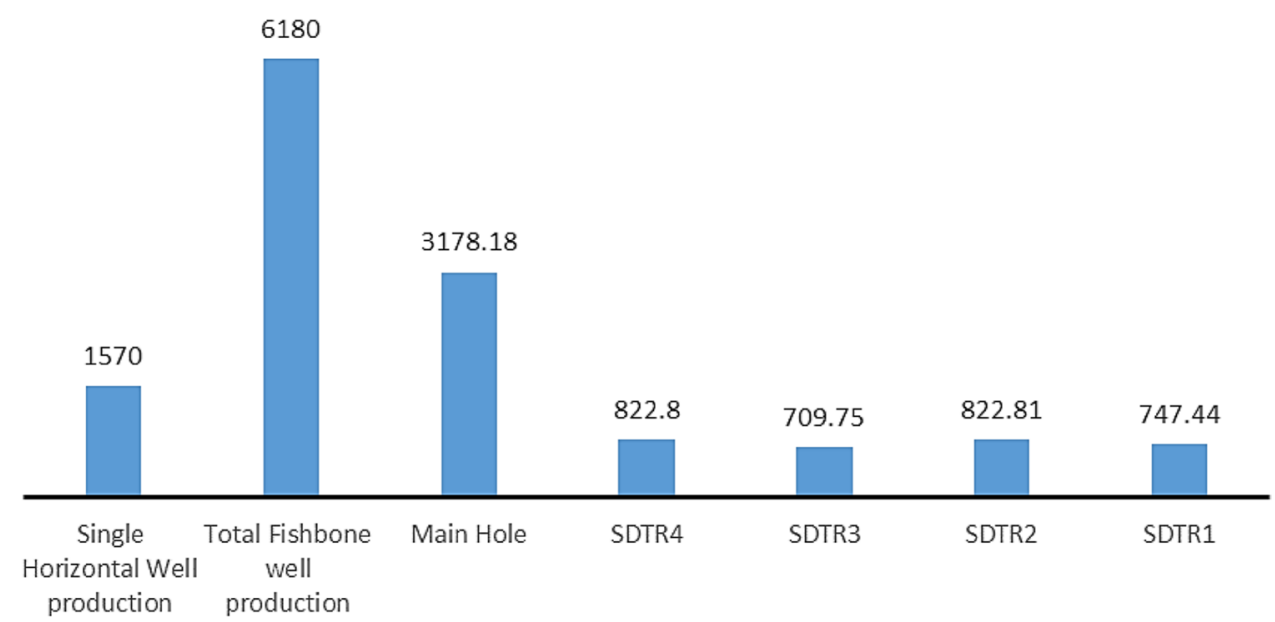




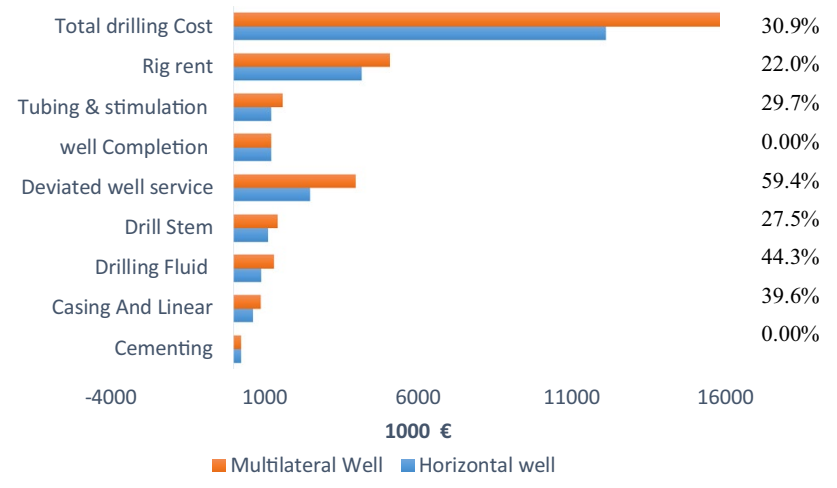

Fig. 11 Comparison of drilling and completion costs for fishbone well and single horizontal well

economical point of view. Based on the current price list of materials, operation cost and services leasing cost in the mentioned oil field, drilling and completion cost estimation has been done for the single horizontal well compared to the alternative fishbone well (Fig. 11). Daily rig operation cost is considered to be $€ 30,000$ in this field, and other expenditures which are affecting total drilling and completion cost are reported in Fig. 11. Undoubtedly, drilling operation costs for drilling more feet tend to raise the costs compared to the single horizontal well. Clearly, drilling time for fishbone well is rationally more than single horizontal well, and consequently, rig rent cost is eminently increased. Fishbone sidetracks were designed as open hole; therefore, cementing and well completion costs remained the same for both cases. On the other hand, deviated well service, by $59.4 \%$ increased expenditure, has the highest additional cost of fishbone well cost compared to the single horizontal well. Although, in almost all of drilling and completion operations, expenditure has been increased as shown in Fig. 11, the total drilling cost has been increased only by $130 \%$. In another word, application of fishbone drilling technology increased production rate by 3.9 times compared to the single horizontal well, while drilling and completion cost was raised only by 1.3 times.

\section{Conclusions}

In conclusion, where the reservoir is thin and low permeable, production can be improved by using longer horizontal sections. The outcome of this study indicated the importance of the horizontal section and lateral lengths of multilateral well on productivity. Application of the multilateral well as an alternative to the single horizontal well showed promising results by increasing $393 \%$ of total production and increasing only $130 \%$ of drilling operation expenditure. Although one of the greatest challenges for the application of multilateral wells is the lack of proper drilling technology, this research showed that by using the same technology for a single horizontal well, multilateral well development is applicable. Another great aspect of multilateral wells for low-permeable and heavy oil reservoirs is production rate enhancement with no need to drill new wells. Therefore, minimizing environmental pollution can be considered as another benefit of multilateral well development. Recovery factor and areal sweep efficiency are suggested as alternative parameters of multilateral wells to be investigated in future studies.

Open Access This article is distributed under the terms of the Creative Commons Attribution 4.0 International License (http://creativeco mmons.org/licenses/by/4.0/), which permits unrestricted use, distribution, and reproduction in any medium, provided you give appropriate credit to the original author(s) and the source, provide a link to the Creative Commons license, and indicate if changes were made.

\section{References}

Ali AG, Lababidi HMS, Ebrahim AS (2004) An integrated approach for the planning and completion of horizontal and multilateral wells. J Petrol Sci Eng 44(3-4):283-301

Ali AG, Lababidi HMS, Ebrahim AS (2005) A web-based expert system for the planning and completion of multilateral wells. J Petrol Sci Eng 49(3-4):162-181

Ayokunle AT, Hashem MH (2016) Design optimization of multilateral wells in heterogeneous reservoirs. In: SPE Kingdom of Saudi Arabia annual technical symposium and exhibition, Dammam, Saudi Arabia

Bera A, Belhaj H (2016) A comprehensive review on characterization and modeling of thick capillary transition zones in carbonate reservoirs. J Unconv Oil Gas Resour 16:76-89

Bilgesu HI, Mishra N, Ameri S (2007) Understanding the effects of drilling parameters on hole cleaning in horizontal and deviated wellbores using computational fluid dynamics. In: SPE eastern regional meeting, SPE

Dang L, Peng P, Zhou G, Chen Z, Phan CV, Walker J, Liu G (2013) First open hole sidetrack in deep horizontal well saves time and lowers cost: a case study. In: International petroleum technology conference

Dongbo HE, Ailin JIA, Guang JI, Yunsheng WEI, Haifa TANG (2013) Well type and pattern optimization technology for large scale tight sand gas, Sulige gas field, NW China. Petrol Exp Dev 40(1):84-95

Economides MJ, Brand CW, Frick TP (1996) Well configurations in anisotropic reservoirs. Society Petrol Eng 11:257-262

Elyasi S (2016) Assessment and evaluation of degree of multilateral well's performance for determination of their role in oil recovery at a fractured reservoir in Iran. Egyptian J Petrol 25(1):1-14

Garrouch AA, Ebrahim AS (2001) Assessment of the stability of inclined wells. In: Presentation at the SPE western regional meeting held in Bakersfield, California, pp 26-30

Guo B, Sun K, Ghalambor A (2008) Well productivity hand book. Gulf Publishing Company, Houston, p 226

Hasan A, Abdulraheem A, Elkatatny S, Ahmed M (2017) New approach to quantify productivity of fishbone multilateral well Amjed. In: SPE annual technical conference and exhibition, San Antonio, Texas, USA




Jinghong H, Zhang C, Rui Z, Yu Y, Chen Z (2017) Fractured horizontal well productivity prediction in tight oil reservoirs. J Petrol Sci, Eng, p 151

Li Y, Bjorndalen N, Kuru E (2007) Numerical modelling of cuttings transport in horizontal wells using conventional drilling fluids. J Can Petrol Technol 46(7):9-15

Mendes S, Albuquerque M, Vento M, Batista N (2014) Successful use of multilateral technology to improve oil recovery in the Brazilian amazon, SPE Latin America and Caribbean Petroleum Engineering Conference, Venezuela

Nawaz K, Al-Faraj OA, Ajmi NA, Awan AH, Verma J, Ganda S (2009) Open hole sidetrack: a transformation in drilling dual lateral Khuff reservoir gas wells in the Kingdom of Saudi Arabia. Society of Petroleum Engineers

Rice K, Jorgensen T, Waters J (2014) First installation of efficient and accurate multilaterals stimulation technology in carbonate oil application. In: Society of Petroleum Engineers, SPE eastern regional meeting, Charleston USA

Wang H, Guo J, Zhang L (2017) A semi-analytical model for multilateral horizontal wells in low-permeability naturally fractured reservoirs. J Petrol Sci Eng 149:564-578
Xiance Y, Guo B, Ai C, Bu Z (2009) A Comparison between multifractured horizontal and fishbone wells for development of lowpermeability fields. In: Asia Pacific Oil and gas conference and exhibition, Jakarta, Indonesia

Xing G, Guo F, Song C, Sun Y, Yu J, Wang G (2012) Fishbone well drilling and completion technology in ultra-thin reservoir. In: Society of Petroleum Engineers, IADC/SPE Asia Pacific drilling technology conference and exhibition, Tianjin, China

Zehao L, Song X, Geng L, Li G (2019) Optimization of multilateral well configuration in fractured reservoirs. J Petrol Sci Eng 172:1153-1164

Zhou S, Sun F, Zeng XJ, Fang FJ (2008) Application of multilateral wells with limited sand production to heavy oil reservoirs. Petrol Exp Dev 35(5):630-635

Publisher's Note Springer Nature remains neutral with regard to jurisdictional claims in published maps and institutional affiliations 